CLINICAL STUDY

\title{
Long-standing, insulin-treated type 2 diabetes patients with complications respond well to short-term resistance and interval exercise training
}

\author{
S F E Praet, R A M Jonkers, G Schep ${ }^{1}$, C D A Stehouwer ${ }^{2}$, H Kuipers, H A Keizer ${ }^{3}$ and L J van Loon \\ Department of Movement Sciences, Nutrition and Toxicology Research Institute Maastricht (NUTRIM), Maastricht University, Maastricht, The \\ Netherlands, ${ }^{1}$ Department of Sports Medicine, Máxima Medical Center, Veldhoven, The Netherlands, ${ }^{2}$ Department of Internal Medicine, Academic Hospital \\ Maastricht, Maastricht, The Netherlands and ${ }^{3}$ Department of Human Physiology and Sports Medicine, Free University of Brussels, Brussels, Belgium \\ (Correspondence should be addressed to S F E Praet who is now at Department of Movement Sciences, Faculty of Health, Medicine and Life Sciences, \\ Maastricht University, PO Box 616,6200 MD Maastricht, The Netherlands; Email: stephan.praet@bw.unimaas.nl)
}

\begin{abstract}
Objective: To determine the feasibility and the benefits of combined resistance and interval exercise training on phenotype characteristics and skeletal muscle function in deconditioned, type 2 diabetes (T2D) patients with polyneuropathy.

Design: Short-term, single-arm intervention trial.

Methods: Eleven male T2D patients (age: $59.1 \pm 7.5$ years; body mass index: $32.2 \pm 4.0 \mathrm{~kg} / \mathrm{m}^{2}$ ) performed progressive resistance and interval exercise training thrice a week for 10 weeks. Besides primary diabetes outcome measures, muscle strength (MUST), maximal workload capacity $\left(W_{\max }\right)$, whole-body peak oxygen uptake $\left(\mathrm{VO}_{2 \text { peak }}\right)$ and muscle oxidative capacity (MUOX), intramyocellular lipid (IMCL) and glycogen (IMCG) storage, and systemic inflammation markers were determined before and after training. Daily exogenous insulin requirements (EIR) and historic individualized EIR were gathered and analysed.

Results: MUST and $W_{\max }$ increased with 17\% (90\% confidence intervals 9-24\%) and 14\% (6-21) respectively. Furthermore, mean arterial blood pressure declined with $5.5 \mathrm{mmHg}(-9.7$ to -1.4$)$. EIR dropped with $5.0 \mathrm{IU} / \mathrm{d}(-11.5$ to 1.5$)$ compared with baseline. A decline of respectively $-0.7 \mathrm{mmol} / \mathrm{l}$ ( -2.9 to 1.5$)$ and $-147 \mu \mathrm{mol} / \mathrm{l}(-296$ to 2$)$ in fasting plasma glucose and non-esterified fatty acids concentrations were observed following the intervention, but these were not accompanied by changes in $\mathrm{VO}_{2 \text { peak }}$, MUOX, IMCL or IMCG, and blood glycolysated haemoglobin, adiponectin, tumor necrosis factor- $\alpha$ and/or cholesterol concentrations.

Conclusion: Short-term resistance and interval exercise training is feasible in deconditioned T2D patients with polyneuropathy and accompanied by moderate improvements in muscle function and blood pressure. Such a specific exercise regimen may provide a better framework for future exercise intervention programmes in the treatment of deconditioned T2D patients.
\end{abstract}

European Journal of Endocrinology 158 163-172

\section{Introduction}

Physical exercise has long been recognized as an effective interventional strategy in the treatment of type 2 diabetes (T2D). The prolonged application of either endurance or the combination of resistance- and endurance-type exercise training has been shown to increase wholebody glucose tolerance and/or insulin sensitivity (1-3) and improve cardiovascular risk profile $(1,3,4)$ in T2D patients. However, studies assessing the effects of exercise training in long-standing, insulin-treated, T2D patients with complications are generally lacking. The latter is partly due to the many difficulties encountered when trying to define an appropriate exercise programme for these patients, who generally suffer from substantial weight gain (5), exercise intolerance and diabetic polyneuropathy (6-8). The level of diabetic polyneuropathy also appears to be associated with general muscle weakness $(9,10)$, impaired physical performance (11), poor glycemic control (12) and a high cardiovascular risk profile (13). As clinical evidence for the health benefits of exercise intervention is quite scarce in this diabetes subpopulation, many patients are generally not advised to participate in intense endurance exercise intervention programmes.

It has been reported that the adaptive response to exercise training is strongly determined by the presence of clinical signs of (autonomic) neuropathy and/or cardiorespiratory deconditioning (14). Therefore, the presence of co-morbidities should be taken into account when tailoring an exercise programme for longstanding, insulin-treated T2D patients. To compensate 
for neuropathy-related muscle weakness and cardiorespiratory fitness levels, it would be advisable to focus on improving muscle strength (15).

Exercise intervention studies in chronic heart failure patients have taught us that short bouts of high-intensity interval training (HIT) represent a safe and effective type of exercise regimen that may increase maximal workload and peak whole-body oxygen uptake capacity $\left(\mathrm{VO}_{2 \text { peak }}\right)$ in deconditioned subjects $(16,17)$. Since exercise intensity and subsequent muscle fibre-type recruitment patterns during resistance exercise and HIT are likely to be similar, HIT on top of resistance exercise could represent an attractive style of exercise training in deconditioned T2D patients. By directly transferring gains in muscle strength into more functional movements, performance capacity for endurance-type activities may also show greater long-term benefits. As the population of long-term diagnosed T2D patients on exogenous insulin therapy is vastly expanding (18), it is of clinical importance to establish whether the combined application of resistance-type exercise and HIT represents a feasible training method in deconditoned T2D patients with polyneuropathy.

Exercise interventions generally aim to maximize the skeletal muscle adaptive response. The latter is based on the fact that skeletal muscle tissue is responsible for $\sim 80 \%$ of whole-body blood glucose disposal (19). Previous studies have shown that changes in muscle fibre-type composition (20-23), muscle oxidative capacity (MUOX) (24) and intramyocellular lipid (IMCL) $(25,26)$ and/or glycogen (25) content are associated with the development of skeletal muscle insulin resistance. Although insulin sensitivity has been reported to improve following resistance (27-29) as well as endurance-type $(2,30-32)$ exercise training, the concomitant structural changes in resting IMCL and/or glycogen content following exercise interventions in T2D patients remain controversial (33-38).

Over the past couple of years, it has been suggested that in the context of cardiorespiratory deconditioning (39) and ectopic fat accumulation (33, 40-43), chronic low-grade inflammation plays an important role in the development of microvascular complications in the insulin-resistant state $(44,45)$. Recent studies indicate that lifestyle interventions modulate circulating adipokine levels and reduce the level of systemic inflammation (46), thereby improving whole-body insulin sensitivity (47). As we aim to investigate both the feasibility and impact of exercise training in long-standing T2D patients with polyneuropathy, it would also be appropriate to assess various markers relevant to the inflammatory state (high sensitivity C-reactive protein (hsCRP), tumor necrosis factor (TNF)- $\alpha$, interleukin (IL)-6 and adiponectin) before and after exercise intervention.

The present study aims to define the feasiblity and the clinical benefits of 10 weeks of resistance- and intervaltype exercise training in long-standing, insulin-treated T2D patients with diabetic polyneuropathy. Furthermore, this study aims to obtain more insight into the structural and metabolic changes that are associated with the skeletal muscle adaptive response to exercise training in these patients.

\section{Methods}

\section{Subjects}

Eleven male T2D patients were selected from an outpatient clinic to participate in this hospital-based case-control intervention study. Subjects had been diagnosed with T2D for over $12.1 \pm 7.0$ years and had been on exogenous insulin treatment for $7.0 \pm 8.0$ years. They had no history of participating in any regular exercise programme for at least 10 years. All subjects had been on a stable regimen of diabetes medication for at least 3 months before being recruited. Patients using thiazolidinediones and/or $\beta$-blockers for less than 6 months, and subjects with impaired liver function (serum-aspartate amino transferase and/or $\gamma$-glutamyltransferase $>2$ times the standard value), macroalbuminuria, severe retinopathy or a history of severe cardiovascular problems were excluded from participation. Furthermore, patients were required to show clinical signs of diabetic polyneuropathy, which was initially determined through history taking and by quantitative sensory testing using a $10 \mathrm{~g}$ Semmes-Weinstein monofilament. Since diabetic polyneuropathy was one of our main inclusion criteria, a complete electrodiagnostic evaluation of four motor (peroneal, tibial, median and ulnar) and three sensory (sural, median and ulnar) nerves using electromyography was performed by an independent clinical neurophysiologist. All conduction velocity and distal amplitude values for the nerve conduction studies (NCS) were given a score of 0 for normal and 1 for abnormal (48). The maximum NCS score if all parameters were abnormal was 28 points (16 motor and 12 sensory). The total NCS score was defined as the sum of the number of abnormal values and is considered abnormal if higher than 3 (48). In accordance, an NCS score of 4 or higher was a prerequisite for inclusion in the study.

Subjects' characteristics are shown in Table 1. Out of the 11 participating subjects, 7 patients were treated with short (Novorapid, $n=6$ ) or rapidly acting insulin (Humulin, $n=1$ ) before each meal either in combination with NPH insulin (Insulatard, $n=5$ ), premixed biphasic isophane insulin (Mixtard 30/70 in combination with metformin, $n=1$ ) or a very long-acting insulin analogue (insulin glargine, $n=1$ ), all administered before bedtime. Three subjects were treated with premixed biphasic isophane insulin twice a day (Mixtard 30/70, $n=3$ ) in combination with metformin. One subject used NPH insulin (Humulin NPH) once a day before breakfast in combination with metformin and a sulphonylurea (glimepiride). Data on daily insulin requirements preceding the study were gathered by a retrospective search through the individual patient 
Table 1 Univariate analyses of subjects' characteristics at baseline and change following 10 weeks of exercise training.

\begin{tabular}{|c|c|c|c|c|}
\hline$n=11$ & Baseline & Change & $90 \% \mathrm{Cl}$ & $P$ value \\
\hline Age (years) & $59.1 \pm 7.5$ & - & & \\
\hline Years since diagnosis T2D & $12.1 \pm 7.0$ & - & & \\
\hline NCS-score (AU) & $15.8 \pm 6.3$ & _ & & \\
\hline Years of exogenous insulin therapy & $7.0 \pm 8.0$ & - & & \\
\hline Daily insulin requirements (IU) & $92.5 \pm 37.0$ & -5.0 & -11.5 to 1.5 & 0.196 \\
\hline Body mass index $\left(\mathrm{kg} / \mathrm{m}^{2}\right)$ & $32.2 \pm 4.0$ & 0.0 & -0.2 to 0.2 & 0.870 \\
\hline Body weight $(\mathrm{kg})$ & $97.6+16.1$ & -0.1 & -0.8 to 0.5 & 0.799 \\
\hline Waist circumference $(\mathrm{cm})$ & $112.6 \pm 12.1$ & -1.1 & -2.8 to 0.7 & 0.286 \\
\hline FFM (kg) & $68.9 \pm 9.6$ & - & & \\
\hline Fat percentage (\%) & $27.0 \pm 2.8$ & _- & & \\
\hline SBP $(\mathrm{mmHg})$ & $147.4 \pm 12.3$ & -7.6 & -15.2 to 0.1 & 0.098 \\
\hline MAP $(\mathrm{mmHg})$ & $105.7 \pm 7.3$ & $-5.5^{\star}$ & -9.7 to -1.4 & 0.036 \\
\hline $\mathrm{DBP}(\mathrm{mmHg})$ & $82.5 \pm 7.1$ & -2.2 & -7.2 to 2.8 & 0.446 \\
\hline$W_{\text {max }}$ RAMP test $(W)$ & $152+39$ & $21^{\ddagger}$ & 10 to 32 & 0.006 \\
\hline $\mathrm{VO}_{2 \text { peak }}$ per $\mathrm{kg} \mathrm{BW} \mathrm{(ml/kg} \mathrm{per} \mathrm{min)}$ & $24.3 \pm 1.4$ & 0.9 & -0.2 to 2.1 & 0.171 \\
\hline$\%$ pred $\mathrm{VO}_{2 \text { peak }}$ & $79.2 \pm 15.1$ & 3.1 & -0.4 to 6.7 & 0.138 \\
\hline$W_{\max }$ Steep RAMP $(W)$ & $275 \pm 62$ & $41^{\ddagger}$ & 27 to 56 & 0.000 \\
\hline 1RM strength LowerB (kg) & $100.6 \pm 23.5$ & $18.0^{\dagger}$ & 8.9 to 27.1 & 0.005 \\
\hline 1RM strength UpperB (kg) & $60.9 \pm 7.3$ & $9.8^{*}$ & 3.2 to 16.4 & 0.023 \\
\hline C-peptide (nmol/l) & $0.77 \pm 0.56$ & 0.07 & -0.12 to 0.26 & 0.520 \\
\hline $\mathrm{HbA}_{1 \mathrm{c}}(\%)$ & $7.63 \pm 0.99$ & -0.18 & -0.54 to 0.18 & 0.386 \\
\hline $\mathrm{FPG}(\mathrm{mmol} / \mathrm{l})$ & $10.2 \pm 3.1$ & -0.71 & -2.9 to 1.5 & 0.568 \\
\hline Total-C/HDL-C ratio & $5.1 \pm 1.2$ & -0.1 & -0.7 to 0.4 & 0.709 \\
\hline LDL-C (mmol/l) & $3.4 \pm 0.4$ & 0.1 & -0.2 to 0.32 & 0.644 \\
\hline Triacylglycerol $(\mathrm{mmol} / \mathrm{l})$ & $2.3 \pm 0.4$ & -0.2 & -0.9 to 0.2 & 0.386 \\
\hline NEFA $(\mu \mathrm{mol} / \mathrm{l})$ & $459+243$ & -147 & -296 to 2 & 0.103 \\
\hline hsCRP (mg/l) & $2.07 \pm 1.77^{\mathrm{a}}$ & 0.21 & -0.38 to 0.80 & 0.532 \\
\hline Adiponectin $(\mu \mathrm{g} / \mathrm{l})$ & $5.4+2.6$ & -0.1 & -0.8 to 0.6 & 0.751 \\
\hline TNF- $\alpha(n g / l)$ & $7.2 \pm 1.5$ & 0.1 & -0.7 to 0.9 & 0.783 \\
\hline
\end{tabular}

Numbers are mean \pm s.D. $90 \% \mathrm{Cl}, 90 \%$ confidence interval; T2D, type 2 diabetes; NCSs, nerve conductions study-score using electromyography (EMG) in arbitrary units, abnormal results are defined as three or more abnormal parameters (48). BMI, body mass index; FFM, fat-free mass; MAP, mean arterial blood pressure $\mathrm{mmHg}$; $W_{\max }$ RAMP test, maximum workload capacity during RAMP: linear incremental (15 or 20 W/min) cycling exercise, or Steep RAMP: cycling protocol of $25 \mathrm{~W} / 10 \mathrm{~s}$ until exhaustion; $\mathrm{VO}_{2 \text { peak }}$ maximal oxygen uptake per kg bodyweight; Relative age-, height-, body weight- and sex-adjusted cardio respiratory fitness (\%Pred. $\mathrm{VO}_{2 \text { peak }}$ ) was based on the equation by Fairbarn et al. (49); $1 \mathrm{RM}$; average 1 repetition maximum (kg) for respective two lower (LowerB) and three upper body (UpperB) exercises; $\mathrm{HbA}_{1 \mathrm{c}}$, glycolysated haemoglobin; FPG, fasting plasma glucose; hsCRP, high sensitivity C-reactive protein; TNF- $\alpha$, tumor necrosis factor alpha; ${ }^{*}$ significant difference, $P<0.05,{ }^{\dagger} P<0.01 ;{ }^{\ddagger} P<0.001$, paired Student's $t$-test.

a Based on $n=10$.

records from the department of Internal Medicine at the Máxima Medical Centre. The nature and the risks of the experimental procedures were explained to the subjects and all gave their written informed consent to participate in the study, which was approved by the local Medical Ethical Committee of the Máxima Medical Center, Veldhoven, The Netherlands.

\section{Body composition}

Body mass and waist circumference were measured using an analogue weight scale and standard measuring tape respectively. Segmental and wholebody bone mass and fat-free mass were determined using whole-body DEXA (Hologic QDR-4500 Discovery A, software version 12.3:3, Hologic Inc, Bedford, MA, USA).

\section{Blood pressure recording}

Before and after the 10 week exercise programme (Fig. 1), systolic and diastolic blood pressure were recorded on two separate occasions during a 15-min supine rest period using a Dinamap 1846SX automatic blood pressure measuring device (model 8262, Critikon, Tampa, FL, USA). Each measurement was performed under standardized supine rest. Mean arterial blood pressure (MAP) was calculated from the last three stable blood pressure measurements (i.e. mean arterial pressure difference $<4 \mathrm{mmHg}$ ) over a 10 -min period during the two separate visits to minimize the influence of day-to-day variation and familiarization to the protocol. Intake and dosage of blood pressure lowering medication was maintained throughout the entire study period.

\section{Peak whole-body oxygen uptake}

$\mathrm{VO}_{2 \text { peak }}$ and maximal workload capacity $\left(W_{\text {max }}\right)$ were measured during an incremental exhaustive exercise test until exhaustion, performed on a cycle ergometer using a linearly increasing (15 or $20 \mathrm{~W} / \mathrm{min}$ ) ramp protocol. Gas exchange measurements were performed continuously (Ergostar, PMS Professional Medical Systems, Basel, Switzerland). Relative age-, height-, body weight- and sex-adjusted cardio respiratory fitness (\%Pred. $\mathrm{VO}_{2 \text { peak }}$ ) was based on the equation by Fairbarn et al. (49). 


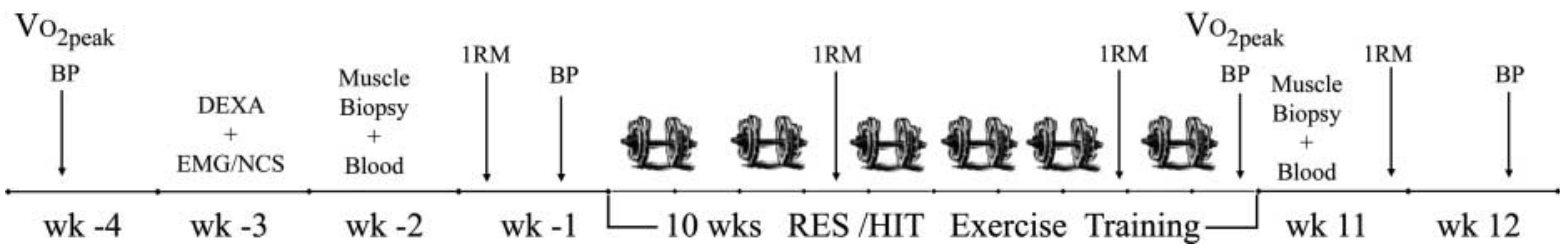

Figure 1 Overview of study protocol, including timing of the different tests before and after the 10-week resistance (RES) and high-intensity interval (HIT) exercise training programme: $\mathrm{VO}_{2 \text { peak }}$, exhaustive cycle ergometry test to determine maximum power output $\left(W_{\text {max }}\right)$ and peak oxygen uptake $\left(\mathrm{VO}_{2 \text { peak }}, \mathrm{ml} / \mathrm{kg}\right.$ per body weight per $\left.\mathrm{min}\right)$; $\mathrm{BP}$, standardized blood pressure recording in supine position; EMG, standardized nerve conduction velocity study (NCS) to assess level of diabetic sensorimotor polyneuropathy; DEXA, dual energy X-ray absorptiometry to assess body composition and fat free mass; muscle biopsy + blood, percutaneous muscle biopsy and venous blood sample during fasting conditions, gathered 3 days following any form of intense physical exercise; 1RM, muscle strength testing for two lower and three upper body exercises.

Cardiac function was monitored using a 12-lead electrocardiogram with heart rate being recorded continuously and sampled at $1 \mathrm{kHz}$ through a data $\log$ device (Co2ntrol).

\section{Strength testing}

At least 1 week before the first exercise session, subjects participated in two exercise trials to become familiarized with the exercise protocol and the equipment. Proper lifting technique was demonstrated and practiced for each of the two lower-limb exercises (leg press and leg extension) and for the three upper-body exercises (shoulder press, horizontal pull and lat pull-down). Maximum strength was estimated using the multiple repetitions testing procedure and at least 1 week before the experimental trial, subjects' 1 repetition maximum (1RM) was determined (50). To individualize the training programme to the level of co-morbidity and subsequently maximize the progress in muscle strength, 1RM strength testing was repeated at 4 and 8 weeks after the start of the training programme after which the absolute exercisetraining intensity was adjusted accordingly (Fig. 1).

\section{Blood sampling and analysis}

Two weeks before the start of the exercise programme and 3 days after the last exercise session, blood and muscle biopsy samples were collected (Fig. 1) to ensure that structural differences in skeletal muscle biochemical and morphological characteristics were not confounded by the acute effects of the last exercise bout (2). On the evening before the blood sample and muscle biopsy collection, subjects received a standardized meal $(35.2 \pm 6.0 \mathrm{~kJ}$ per $\mathrm{kg}$ body weight (BW), containing 53 energy\% (En\%) fat, $10 \mathrm{En} \%$ protein and $37 \mathrm{En} \%$ carbohydrate) after which subjects remained fasted till the next morning. Subjects reported at the laboratory at $0800 \mathrm{~h}$. Venous blood samples were collected, immediately centrifuged at $1000 \mathrm{~g}$ and $4{ }^{\circ} \mathrm{C}$ for $10 \mathrm{~min}$, after which aliquots of plasma were frozen immediately in liquid nitrogen and stored at $-80{ }^{\circ} \mathrm{C}$ until analyses. Fasting plasma glucose (FPG), serum cholesterol, high-density lipoprotein
(HDL)-cholesterol, low-density lipoprotein (LDL)-cholesterol, non-esterified fatty acids (NEFA) and triacylglycerol concentrations were analysed with the Cobas Fara semi-automatic analyzer (Roche Diagnostics). Blood glycolysated haemoglobin $\left(\mathrm{HbA}_{1 \mathrm{c}}\right)$ content was determined through HPLC (Bio-Rad Diamat). The serum concentration of adiponectin was quantified using a commercially available Human Adiponectin ELISA (\#HADP-61K, Linco Research Inc., St Charles, MO, USA). TNF- $\alpha$ concentration was analysed using a solidphase, chemiluminescent immunometric assay (IMMULITE TNF- $\alpha$, DPC Biermann GmbH, Bad Nauheim, Germany). hsCRP was measured by means of immunoephelometry (Cardiophase, Dade Behring GmbH). C-peptide was analysed through an electrochemiluminiscent immunoassay (\#03184897, Roche $\mathrm{GmbH}$ ).

\section{Muscle biopsy and immunohistochemical analyses}

After blood sample collection, a percutaneous muscle biopsy was collected from the Musculus vastus lateralis. Muscle samples were freed from any visible non-muscle material, mounted in embedding medium (Tissue-Tek, Sakura Finetek, Zoeterwoude, The Netherlands) and frozen in liquid nitrogen-cooled isopentane $\left(-160{ }^{\circ} \mathrm{C}\right)$ and stored at $-80^{\circ} \mathrm{C}$.

For histochemical analyses, multiple serial transverse cryosections $(5 \mu \mathrm{m})$ from biopsy samples were collected and thaw-mounted together on uncoated, pre-cleaned glass slides for each subject. To permit the determination of muscle fibre intramyocellular lipid (IMCL) content stained by oil red $O$ together with immunolabelled cellular constituents, we used the protocol as previously described (51). The proportion of types I, IIa and IIx muscle fibres was determined by ATPase staining (52). To assess intramyocellular glycogen content, we used the modified periodic acid Schiff stain as recently described (53), allowing direct, fibre-type-specific determination of muscle glycogen content. Muscle fibre-type-specific oxidative capacity was estimated by determining succinate dehydrogenase (SDH) activity in the muscle cross sections using histochemical staining (54). 


\section{Training procedures}

The backbone of the exercise programme was progressive resistance training (PRT), with HIT protocol as a supplement. Four bouts of resistance-type exercise targeting the upper body were performed ( $2 \times 10$ reps of $50 \%$ of $1 \mathrm{RM})$. Thereafter, resistance training was continued with horizontal leg press and leg extension $(2 \times 10$ reps). After 5 weeks, the intensity of the PRT was progressively increased from 50 to $60 \% 1 \mathrm{RM}$ to accommodate for the generally deconditoned state of our patients and minimize the risk of musculoskeletal overuse injuries. In each session, PRT was followed by multiple bouts of HIT to predominantly stress type II muscle fibres of the working leg muscle without overloading the cardiovascular system (55). In heart failure patients, HIT exercise has been shown to increase $\mathrm{VO}_{2 \text { peak }}$ and $W_{\text {max }}$, while exertion levels were perceived as moderate (16). Both numbers of bouts and work rate for the interval modes were progressively increased. The HIT included 4-8 cycling bouts of $30 \mathrm{~s}$, at $50-60 \%$ of the maximum achieved $W_{\max }$ during a steep ramp test (increments of $25 \mathrm{~W} / 10 \mathrm{~s}$, (55)) alternated with $60 \mathrm{~s}$ of unloaded cycling. In total, a single training session required $\sim 45 \mathrm{~min}$ to complete. All subjects were verbally encouraged during the trainings sessions to complete the entire protocol.

Postprandial blood glucose was monitored before and after exercise using a capillary blood glucose meter (Glucocard Memory PC, Menarini Diagnostics, Berelux, Valkenswaard, The Netherlands). If blood glucose was $<6.0 \mathrm{mmol} / \mathrm{l}$ before the start of the exercise session, a snack with $30 \mathrm{~g}$ carbohydrate and $5 \mathrm{~g}$ protein was provided. Glucose monitoring log sheets were provided to subjects' diabetic nurse and diabetologist for follow-up care. If hypoglycemia occurred more than twice following an exercise session, the diabetic nurse was consulted to adjust exogenous insulin dose.

\section{Statistical analysis}

All data are expressed as means \pm s.D. Repeated measures ANOVA and paired Student's $t$-test were applied to compare the physical, biochemical and immunohistochemical test results before and after the 10 weeks of exercise, using the SPSS 12.0.1 software package (SPSS Inc., Chicago, IL, USA). Level of statistical significance was set at $P<0.05$. Given the experimental nature of a small-scale feasibility study, $90 \%$ confidence intervals (CI) of the changes were calculated to assess the chances of benefit and harm. In accordance with Snowling and Hopkins (3), clinically important changes of the between-subject standard deviation at baseline were interpreted using thresholds of $0.2,0.6$ and 1.2 for small, moderate and large respectively.

\section{Results}

\section{Subjects' characteristics}

Subjects' characteristics are shown in Table 1. Relative baseline cardiorespiratory fitness (\%pred $\mathrm{VO}_{2 \text { peak }}$ ) was $79.2 \pm 15.1 \%$. Mean duration of T2D was $12.1 \pm 7.0$ years since diagnosis, and subjects had been on exogenous insulin therapy for $7.0 \pm 8.0$ years. The average insulin doses over a 2 -year period prior to the study were raised from $64.1 \pm 38.0 \mathrm{IU} / \mathrm{d}$ towards $92.5 \pm 37.0 \mathrm{IU} / \mathrm{d}$ before entering the study. This represents an average increase in insulin dose of $+3.6 \pm 2.6 \mathrm{IU} / \mathrm{d}$ per 3 month period. Under normal clinical conditions, the latter would have resulted in (virtual) daily exogenous insulin requirements (EIR) of $96.3 \pm 37 \mathrm{IU} / \mathrm{d}$. After 10 weeks of training, the average daily dose of exogenous insulin dropped to $87.7 \pm$ $37.0 \mathrm{IU} / \mathrm{d}$, representing a virtual improvement of $-8.6 \mathrm{IU} / \mathrm{d}(90 \% \mathrm{CI}:-15.6$ to $-1.5 \mathrm{IU} / \mathrm{d})$ from the expected trend of increasing exogenous insulin dose. All subjects finished the 10-week training programme. A total of four subjects reported mild and uncomplicated hypoglycaemia (capillary blood glucose $2.7-3.8 \mathrm{mmol} / \mathrm{l}$ ) following the fourth $(n=2)$ and nineth $(n=2)$ exercise session. Only one out of the four subjects required multiple adjustments of exogenous insulin dosage to prevent recurrent exercise-induced hypoglycaemia. One subject developed an overload injury of the knee after 4 weeks of training that limited further progression of the training intensity. Compliance to the programme was good with a mean participation rate of $83 \pm 13 \%$ of all available training sessions.

\section{Anthropometry, blood pressure and physical performance measures}

Table 1 shows the results of all physical and biochemical tests performed before and after 10 weeks of training. Body weight and waist circumferences remained constant throughout the training period. Both systolic blood pressure and MAP were reduced by $7.6 \mathrm{mmHg}(-15.2$ to 0.1$)$ and $5.5 \mathrm{mmHg}(-9.7$ to -1.4$)$ respectively. Maximum power output during the ramp test on the cycle ergometer increased with $14 \%(6-21)$ or $+21 \mathrm{~W}(10-$ 32 ). Both maximum power output during a steep ramp test and overall muscle strength improved with 17 (9-24) and $17 \%(10-24)$ respectively over the 10-week intervention period. $\mathrm{VO}_{2 \text { peak }}$ remained constant, with an average change of $0.9 \mathrm{ml} / \mathrm{kg}$ per BW per min (-0.2 to 2.1 ).

\section{Plasma analyses}

Table 1 summarizes all biochemical analyses of the blood samples. Except for small changes of $-0.71 \mathrm{mmol} / \mathrm{l}$ $(-2.9$ to 1.5$)$ in FPG and $-147 \mu \mathrm{mol} / \mathrm{l}(-296$ to 2$)$ in plasma NEFA concentration, no changes in blood hsCRP, TNF- $\alpha, \mathrm{C}$-peptide, $\mathrm{HbA}_{1 \mathrm{c}}$, lipid profile, triglyceride 
Table 2 Skeletal muscle tissue characteristics.

\begin{tabular}{|c|c|c|c|c|}
\hline Characteristic & Baseline & Change & $90 \% \mathrm{Cl}$ & $P$ value \\
\hline Mixed muscle SDH activity (AU) & $54 \pm 28$ & -5 & -16 to 7 & 0.522 \\
\hline SDH activity type I fibres (AU) & $26 \pm 16$ & 0 & -10 to 10 & 0.995 \\
\hline SDH activity type Ila fibres (AU) & $20 \pm 11$ & 0 & -5 to 5 & 0.992 \\
\hline SDH activity type IIx fibres (AU) & $8 \pm 4$ & -4 & -6 to -3 & 0.006 \\
\hline Mixed muscle ORO activity (AÚ) & $12 \pm 3$ & 4 & -2 to 9 & 0.327 \\
\hline ORO activity type I fibres (AU) & $8 \pm 2$ & 2 & -2 to 6 & 0.364 \\
\hline ORO activity type lla fibres (AU) & $3 \pm 1$ & 2 & -0 to 4 & 0.185 \\
\hline ORO activity type IIx fibres (AU) & $1 \pm 0$ & 0 & -0 to 0 & 0.688 \\
\hline Mixed muscle PAS activity (AU) & $28 \pm 2$ & -1 & -5 to 2.5 & 0.662 \\
\hline PAS activity type I fibres (AU) & $16 \pm 5$ & 0 & -3 to 3 & 0.934 \\
\hline PAS activity type Ila fibres (AU) & $9 \pm 1$ & 1 & -1 to 4 & 0.326 \\
\hline PAS activity type IIx fibres (AU) & $3 \pm 4$ & -3 & -5 to 0 & 0.123 \\
\hline
\end{tabular}

Skeletal muscle characteristics at baseline and absolute change following 10 weeks of resistance and interval exercise training. $90 \% \mathrm{Cl}$, $90 \%$ confidence interval. $P$ value for paired Student's $t$-test Muscle fibre-type distribution was based on individual samples of $>300$ fibres used for the SDH, ORO and PAS stain analyses; $\mathrm{SDH}$, succinate dehydrogenase stain activity (mean \pm S.D.) in arbitrary units as measured by immunohistochemistry indicates the amount of mitochondrial enzyme activity; ORO, oil red $\mathrm{O}$ stain activity (mean \pm s.D.) in arbitrary units as measured by immunohistochemistry as a measure of intramyocellular triglyceride concentration; PAS, periodic acid-Schiff stain activity in arbitrary units (mean \pm s.D.) as measured by immunohistochemistry indicates the glycogen content inside the muscle fibres. Fibre-type-specific content of SDH, ORO and PAS stain activity is corrected for area and number of fibres.

or adiponectin concentrations were detected following the 10-week exercise programme.

\section{Immunohistochemical analyses}

Table 2 summarizes both mixed and fibre-type-specific IMCL and glycogen content and muscle fibre oxidative capacity before and after 10 weeks of resistance exercise. The training programme employed in the present study did not result in any significant changes in absolute IMCL, glycogen or SDH content in types I, IIa and IIx or mixed muscle fibres (Table 2, P>0.05). IMCL, glycogen or SDH content of individual muscle fibres was significantly higher in type I than types IIa and IIx muscle fibres $(P<0.05)$ both before and after 10 weeks of exercise. Muscle fibretype distribution and muscle fibre cross-sectional area did not differ between pre-training (type I, $47 \pm 7 \%$ / $867 \pm 3482 \mu \mathrm{m}^{2}$; type IIa, $41 \pm 8 \% / 7700 \pm 2225 \mu \mathrm{m}^{2}$; type IIx, $16 \pm 8 \% / 5250 \pm 1847 \mu^{2}$ ) and post-training conditions (type I, $45 \pm 10 \% / 7831 \pm 2667 \mu \mathrm{m}^{2}$; type

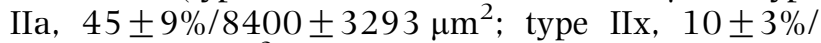
$4704 \pm 2040 \mu^{2}$ ) after the 10 -week resistance exercise programme $(P>0.05)$.

\section{Discussion}

In the present study, we show that 10 weeks of supervised resistance and HIT significantly improves muscle strength, workload capacity and blood pressure regulation in long-standing, insulin-treated T2D patients with diabetic polyneuropathy. Diabetic polyneuropathy is an important factor in the development of peripheral muscle weakness in diabetes patients (10). The associated loss of muscle strength is an underestimated but disabling problem (9) that has been associated with impaired physical function (11) and poor glycemic control (12). Due to the impaired functional capacity, generic exercise intervention programmes designed to prevent and/or treat chronic metabolic disease are generally not applicable in long-standing, insulin-treated T2D patients with diabetic polyneuropathy. Alternatively, resistance training has been proposed to augment functional capacity before participation in the more generic endurance exercise intervention programmes. Since the population of long-standing, insulin-treated T2D patients with complications is vastly expanding (18), it is of important clinical relevance to assess the response to exercise training in these patients. In the present exercise intervention, we focus to improve muscle strength and exercise capacity to compensate for neuropathy-related muscle weakness in deconditioned T2D patients.

Following 10 weeks of moderate intensity exercise training consisting of resistance and relatively highintensity interval exercise, we established a $17 \pm 14$ and $14 \pm 13 \%$ increase in muscle strength and workload capacity respectively. Previous resistance-type exercise intervention studies in uncomplicated T2D patients have applied higher-intensity exercise and reported strength increases between 25 and 75\% (29, 56-60). Some of these intervention studies report significant improvements in $\mathrm{HbA}_{1 \mathrm{c}}(56,57)$, and glucose area under the curve $(58,61)$. No such improvements in glycemic control were observed in this feasibility study. In line with recent findings by Sigal et al. (62), this might be related to the fact that resistance-type exercise is insufficient to further improve glycemic control when baseline $\mathrm{HbA}_{1 \mathrm{c}}$ levels approach 7.5\%. However, given the lack of a control group in our feasibility study, it is not expedient to speak of an attenuated training response. Besides baseline $\mathrm{HbA}_{1 \mathrm{c}}$, numerous other factors, such as training volume, exercise intensity, (3), diet (63) or medication $(15,64)$, prohibit us to compare the different studies. Nevertheless, future exercise intervention studies in long-standing T2D 
patients should consider the level of neuropathy and muscle wasting. Our short-term exercise intervention study indicates that, despite these disabling co-morbidities, moderate improvements in muscle strength are feasible in long-standing T2D patients with diabetic neuropathy. In accordance with other resistance-type exercise training studies in $\mathrm{T} 2 \mathrm{D}(57,60)$, improvements in muscle strength and workload capacity were accompanied by a moderate reduction in MAP (Table 1). Although this is an interesting finding, the underlying mechanisms cannot be deducted from our feasibility study and are likely to be multi-factorial (65). Nevertheless, the potential cardiovascular benefits for patients with long-standing T2D warrant further investigation.

Based on the experience with deconditioned heart failure patients (16), we implemented HIT as a supplement to moderate-intensity PRT. HIT is considered an attractive training stimulus since it stresses the working leg muscles without overloading the cardiovascular system or causing feelings of dyspnoea (55). Our combined short-term exercise intervention effectively improved $W_{\max }$ (Table 1). Despite the improvement in $W_{\text {max }}$, MUOX (SDH enzyme activity) and $\mathrm{VO}_{2 \text { peak }}$ did not increase significantly. Compared with a training study with younger and early-diagnosed T2D patients (66), it could be speculated that the implemented intensity, duration and frequency of exercise in the present study may have restricted an upregulation of myocellular

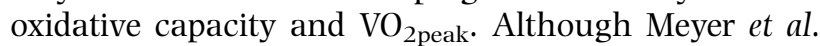
reported improvements in whole-body oxygen uptake capacity in heart failure patients following HIT exercise training (16), the present study indicates that the regular application of 4-8 exercise bouts of $30 \mathrm{~s}$ is insufficient to stress mitochondrial respiration in peripheral skeletal muscle (Table 2). However, this lack of response might also be attributed to our selected subject population, as it has been reported that genetic factors (67), older age (68) and diabetes-related co-morbidities attenuate the adaptive response in $\mathrm{VO}_{2 \text { peak }}(14,61,64,69)$. Therefore, larger-scale studies are needed to gain more insight into the muscle fibre-type-specific adaptation following resistance, interval, endurance or combined types of exercise training in different T2D subpopulations.

The present study supports the notion that intermediate exercise programmes are warranted to bring more deconditioned patients with long-standing T2D to a level at which they will be able to participate in more generic diabetes intervention programmes. Our results indicate that a well-designed exercise regimen composed of short, relatively high-intensity, intermittent exercise bouts is both feasible and safe. Therefore, intermediate exercise intervention programmes prescribing such an exercise regimen could be of great value to increase muscle strength and functional performance in deconditioned T2D patients with polyneuropathy.

Insulin resistance and visceral adiposity $(41-43)$ as well as low cardiorespiratory fitness (39) have been associated with a state of chronic inflammation and ectopic fat accumulation in liver (40) and muscle (33) tissue. Therefore, in the present study, we investigated whether markers for systemic inflammation and lipid abnormalities would change following a short-term exercise intervention. In contrast to previous work (47, 70), we did not observe changes in parameters for chronic inflammation (Table 1). The apparant discrepancy might be attributed to differences in types of exercise, exercise intensity, a more prolonged intervention period, the use of cholesterol lowering agents (71, 72) or simply because of the selected T2D subpopulation. In accordance, comparative and more detailed exercise intervention studies will be required to study the complex metabolic interaction between muscle, liver and fat tissue (73).

We observed small, but clinically relevant improvements in FPG following the exercise intervention (Table 1). The latter was accompanied with an attenuated rise in EIR (Table 1). In the present study, we did not apply hyperinsulinemic euglycemic clamping to assess whole-body insulin sensivity as the latter are likely to interfere with EIR. Therefore, we can only speculate whether the observed trends in reduced FPG and attenuated rise in EIR are the result of structural changes in hepatic and/or peripheral insulin sensitivity or exercise-induced improvements in $\beta$-cell function (74). From a clinical perspective, the feasibility of the combined application of resistance and interval training seems promising in more advanced stages of T2D, which is generally associated with a progressive worsening of glycemic control despite increasing exogenous insulin doses (75).

Lowered peak oxygen uptake and elevated IMCL and glycogen contents have been associated with the development of insulin resistance and/or T2D (25). Despite the significant gain in functional performance, we observed no structural changes in fibre-type specific IMCL, glycogen or SDH content in types I, IIa and IIx or mixed muscle fibres in M. vastus lateralis (Table 2). Furthermore, fibre-type composition had not changed after 10 weeks of exercise intervention. In accordance, improvements in insulin sensitivity following resistancetype exercise training (27-29) have been shown to occur independent of structural changes in skeletal muscle and/ or IMCL and/or glycogen contents (33). Previous studies have either reported no change (76-78), a decrease (79) or even an increase $(80,81)$ in IMCL content after exercise training. As such, we expand on previous findings that the reported improvements in physical fitness, muscle strength as well as the attenuated rise in EIR are not necessarily accompanied by significant changes in muscle fibre-type characteristics, MUOX and/or muscle lipid and/or glycogen content.

Long-term adherence to resistance-type exercise training in T2D patients has proven problematic (82). Therefore, proper supervision is considered an important factor to maintain programme adherence (82). Even 
though we implemented three exercise sessions per week, subjects showed excellent compliance $(83 \pm 13 \%$ attendance of the training sessions) and no dropout. The greater workload capacity and increased strength following the 10-week intervention should be sufficient to enable these patients to participate in a more generic exercise intervention programmes. As such, the applied exercise regimen might represent an effective interventional strategy to enable patients to pursue a more active, healthier lifestyle.

In conclusion, the combined application of resistanceand interval-type exercise training improves physical work-load capacity, lowers resting blood pressure and attenuates the progressive rise in EIR in long-standing, insulin-treated T2D patients with diabetic polyneuropathy. Such a specific exercise regimen may provide a better framework for future exercise intervention programmes in the treatment of deconditioned T2D patients.

\section{Acknowledgements}

This study was made possible with a grant from the Ministry of Health, Welfare and Sport. The electrodiagnostic assessments by our clinical neurophysiologist Ad Smets as well as the assistance from the nurses and staff at the Department of Internal Medicine at the Máxima Medical Center are both greatly acknowledged. The exercise testing equipment was kindly provided by Stans van der Poel from Energy Control BV. The authors would like to thank Jaap Swolfs, Paul Rietjens and Paul Chatrou for supervising the exercise programme.

\section{References}

1 Balducci S, Leonetti F, Di Mario U \& Fallucca F. Is a long-term aerobic plus resistance training program feasible for and effective on metabolic profiles in type 2 diabetic patients? Diabetes Care 200427 841-842.

2 Dela F, Larsen JJ, Mikines KJ, Ploug T, Petersen LN \& Galbo H. Insulin-stimulated muscle glucose clearance in patients with NIDDM. Effects of one-legged physical training. Diabetes $19954 \mathbf{4}$ 1010-1020.

3 Snowling NJ \& Hopkins WG. Effects of different modes of exercise training on glucose control and risk factors for complications in type 2 diabetic patients: a meta-analysis. Diabetes Care 200629 2518-2527.

4 Santeusanio F, Di Loreto C, Lucidi P, Murdolo G, De Cicco A, Parlanti N, Piccioni F \& De Feo P. Diabetes and exercise. Journal of Endocrinological Investigation 200326 937-940.

5 Heller S. Weight gain during insulin therapy in patients with type 2 diabetes mellitus. Diabetes Research and Clinical Practice 200465 S23-S27.

6 Reenders K, De Nobel E, Van Den Hoogen HJ, Rutten GE \& Van Weel C. Diabetes and its long-term complications in general practice: a survey in a well-defined population. Family Practice $199310169-172$.
7 Franklin GM, Kahn LB, Baxter J, Marshall JA \& Hamman RF. Sensory neuropathy in non-insulin-dependent diabetes mellitus. The San Luis Valley Diabetes Study. American Journal of Epidemiology 1990131 633-643.

8 Franklin GM, Shetterly SM, Cohen JA, Baxter J \& Hamman RF. Risk factors for distal symmetric neuropathy in NIDDM. The San Luis Valley Diabetes Study. Diabetes Care 199417 1172-1177.

9 Andersen H, Nielsen S, Mogensen CE \& Jakobsen J. Muscle strength in type 2 diabetes. Diabetes 200453 1543-1548.

10 Volpato S, Blaum C, Resnick H, Ferrucci L, Fried LP \& Guralnik JM. Comorbidities and impairments explaining the association between diabetes and lower extremity disability: The Women's Health and Aging Study. Diabetes Care 200225 678-683.

11 Sayer AA, Dennison EM, Syddall HE, Gilbody HJ, Phillips DI \& Cooper C. Type 2 diabetes, muscle strength, and impaired physical function: the tip of the iceberg? Diabetes Care $2005282541-2542$.

12 De Rekeneire N, Resnick HE, Schwartz AV, Shorr RI, Kuller LH, Simonsick EM, Vellas B \& Harris TB. Diabetes is associated with subclinical functional limitation in nondisabled older individuals: the health, aging, and body composition study. Diabetes Care 2003 26 3257-3263.

13 Wei M, Gibbons LW, Kampert JB, Nichaman MZ \& Blair SN. Low cardiorespiratory fitness and physical inactivity as predictors of mortality in men with type 2 diabetes. Annals of Internal Medicine 2000132 605-611.

14 Howorka K, Pumprla J, Haber P, Koller-Strametz J, Mondrzyk J \& Schabmann A. Effects of physical training on heart rate variability in diabetic patients with various degrees of cardiovascular autonomic neuropathy. Cardiovascular Research 199734 206-214.

15 Sigal RJ, Kenny GP, Wasserman DH, Castaneda-Sceppa C \& White RD. Physical activity/exercise and type 2 diabetes: a consensus statement from the American Diabetes Association. Diabetes Care 200629 1433-1438.

16 Meyer K, Samek L, Schwaibold M, Westbrook S, Hajric R, Beneke R, Lehmann M \& Roskamm H. Interval training in patients with severe chronic heart failure: analysis and recommendations for exercise procedures. Medicine and Science in Sports and Exercise $199729306-312$.

17 Meyer K, Stengele E, Westbrook S, Beneke R, Schwaibold M, Gornandt L, Lehmann M \& Roskamm H. Influence of different exercise protocols on functional capacity and symptoms in patients with chronic heart failure. Medicine and Science in Sports and Exercise $19962 \mathbf{2 8} 1081-1086$.

18 Detournay B, Raccah D, Cadilhac M \& Eschwege E. Epidemiology and costs of diabetes treated with insulin in France. Diabetes and Metabolism 200531 3-18.

19 Defronzo RA, Ferrannini E, Sato Y, Felig P \& Wahren J. Synergistic interaction between exercise and insulin on peripheral glucose uptake. Journal of Clinical Investigation $1981 \mathbf{6 8} 1468-1474$.

20 Marin P, Andersson B, Krotkiewski M \& Bjorntorp P. Muscle fiber composition and capillary density in women and men with NIDDM. Diabetes Care 199417 382-386.

21 Hickey MS, Carey JO, Azevedo JL, Houmard JA, Pories WJ, Israel RG \& Dohm GL. Skeletal muscle fiber composition is related to adiposity and in vitro glucose transport rate in humans. American Journal of Physiology 1995268 E453-E457.

22 Tanner CJ, Barakat HA, Dohm GL, Pories WJ, Macdonald KG, Cunningham PR, Swanson MS \& Houmard JA. Muscle fiber type is associated with obesity and weight loss. American Journal of Physiology. Endocrinology and Metabolism 2002282 E1191-E1196.

23 Venojarvi M, Puhke R, Hamalainen H, Marniemi J, Rastas M, Rusko H, Nuutila P, Hanninen O \& Aunola S. Role of skeletal muscle-fibre type in regulation of glucose metabolism in middle-aged subjects with impaired glucose tolerance during a long-term exercise and dietary intervention. Diabetes, Obesity and Metabolism 20057 745-754.

24 Daugaard JR \& Richter EA. Relationship between muscle fibre composition, glucose transporter protein 4 and exercise training: possible consequences in non-insulin-dependent diabetes mellitus. Acta Physiologica Scandinavica $2001171267-276$. 
25 He J \& Kelley DE. Muscle glycogen content in type 2 diabetes mellitus. American Journal of Physiology. Endocrinology and Metabolism 2004287 E1002-E1007.

26 Morino K, Petersen KF \& Shulman GI. Molecular mechanisms of insulin resistance in humans and their potential links with mitochondrial dysfunction. Diabetes 200655 S9-S15.

27 Ibanez J, Izquierdo M, Arguelles I, Forga L, Larrion JL, GarciaUnciti M, Idoate F \& Gorostiaga EM. Twice-weekly progressive resistance training decreases abdominal fat and improves insulin sensitivity in older men with type 2 diabetes. Diabetes Care 2005 28 662-667.

28 Duncan GE, Perri MG, Theriaque DW, Hutson AD, Eckel RH \& Stacpoole PW. Exercise training, without weight loss, increases insulin sensitivity and postheparin plasma lipase activity in previously sedentary adults. Diabetes Care 200326 557-562.

29 Ishii T, Yamakita T, Sato T, Tanaka S \& Fujii S. Resistance training improves insulin sensitivity in NIDDM subjects without altering maximal oxygen uptake. Diabetes Care 199821 1353-1355.

30 Dela F, Ploug T, Handberg A, Petersen LN, Larsen JJ, Mikines KJ \& Galbo H. Physical training increases muscle GLUT4 protein and mRNA in patients with NIDDM. Diabetes $199443862-865$.

31 Perseghin G, Price TB, Petersen KF, Roden M, Cline GW, Gerow K, Rothman DL \& Shulman GI. Increased glucose transportphosphorylation and muscle glycogen synthesis after exercise training in insulin-resistant subjects. New England Journal of Medicine 1996335 1357-1362.

32 Rogers MA, Yamamoto C, Hagberg JM, Martin WH, III, Ehsani AA \& Holloszy JO. Effect of $6 \mathrm{~d}$ of exercise training on responses to maximal and sub-maximal exercise in middle-aged men. Medicine and Science in Sports and Exercise 198820 260-264.

33 Van Loon LJ \& Goodpaster BH. Increased intramuscular lipid storage in the insulin-resistant and endurance-trained state. Pflügers Archiv $2006 \mathbf{4 5 1}$ 606-616.

34 Koopman R, Manders RJ, Jonkers RA, Hul GB, Kuipers H \& Van Loon LJ. Intramyocellular lipid and glycogen content are reduced following resistance exercise in untrained healthy males. European Journal of Applied Physiology 200696 525-534.

35 Chilibeck PD, Syrotuik DG \& Bell GJ. The effect of strength training on estimates of mitochondrial density and distribution throughout muscle fibres. European Journal of Applied Physiology and Occupational Physiology $199980604-609$.

36 Colberg SR, Hagberg JM, Mccole SD, Zmuda JM, Thompson PD \& Kelley DE. Utilization of glycogen but not plasma glucose is reduced in individuals with NIDDM during mild-intensity exercise. Journal of Applied Physiology 199681 2027-2033.

37 Allenberg K, Johansen K \& Saltin B. Skeletal muscle adaptations to physical training in type II (non-insulin-dependent) diabetes mellitus. Acta Medica Scandinavica 1988223 365-373.

38 Vestergaard H. Studies of gene expression and activity of hexokinase, phosphofructokinase and glycogen synthase in human skeletal muscle in states of altered insulin-stimulated glucose metabolism. Danish Medical Bulletin 199946 13-34.

39 Aronson D, Sella R, Sheikh-Ahmad M, Kerner A, Avizohar O, Rispler S, Bartha P, Markiewicz W, Levy Y \& Brook GJ. The association between cardiorespiratory fitness and C-reactive protein in subjects with the metabolic syndrome. Journal of the American College of Cardiology 200444 2003-2007.

40 Utzschneider KM \& Kahn SE. Review: the role of insulin resistance in nonalcoholic fatty liver disease. Journal of Clinical Endocrinology and Metabolism 200691 4753-4761.

41 Xu H, Barnes GT, Yang Q, Tan G, Yang D, Chou CJ, Sole J, Nichols A, Ross JS, Tartaglia LA \& Chen H. Chronic inflammation in fat plays a crucial role in the development of obesity-related insulin resistance. Journal of Clinical Investigation $2003 \mathbf{1 1 2}$ 1821-1830.

42 Kriketos AD, Greenfield JR, Peake PW, Furler SM, Denyer GS, Charlesworth JA \& Campbell LV. Inflammation, insulin resistance, and adiposity: a study of first-degree relatives of type 2 diabetic subjects. Diabetes Care 200427 2033-2040.

43 Kahn SE, Zinman B, Haffner SM, O'neill MC, Kravitz BG, Yu D, Freed MI, Herman WH, Holman RR, Jones NP, Lachin JM \&
Viberti GC. Obesity is a major determinant of the association of $\mathrm{C}$-reactive protein levels and the metabolic syndrome in type 2 diabetes. Diabetes $2006552357-2364$.

44 Singleton JR, Smith AG, Russell JW \& Feldman EL. Microvascular complications of impaired glucose tolerance. Diabetes $2003 \mathbf{5 2}$ 2867-2873.

45 Spijkerman AM, Gall MA, Tarnow L, Twisk JW, Lauritzen E, LundAndersen H, Emeis J, Parving HH \& Stehouwer CD. Endothelial dysfunction and low-grade inflammation and the progression of retinopathy in type 2 diabetes. Diabetic Medicine $2007 \mathbf{2 4}$ 969-976.

46 Aas AM, Seljeflot I, Torjesen PA, Diep LM, Thorsby PM \& Birkeland KI. Blood glucose lowering by means of lifestyle intervention has different effects on adipokines as compared with insulin treatment in subjects with type 2 diabetes. Diabetologia $200649872-880$.

47 Oberbach A, Tonjes A, Kloting N, Fasshauer M, Kratzsch J, Busse MW, Paschke R, Stumvoll M \& Bluher M. Effect of a 4 week physical training program on plasma concentrations of inflammatory markers in patients with abnormal glucose tolerance. European Journal of Endocrinology 2006154 577-585.

48 Perkins BA, Olaleye D, Zinman B \& Bril V. Simple screening tests for peripheral neuropathy in the diabetes clinic. Diabetes Care 2001 24 250-256.

49 Fairbarn MS, Blackie SP, Mcelvaney NG, Wiggs BR, Pare PD \& Pardy RL. Prediction of heart rate and oxygen uptake during incremental and maximal exercise in healthy adults. Chest 1994 105 1365-1369.

50 Reynolds JM, Gordon TJ \& Robergs RA. Prediction of one repetition maximum strength from multiple repetition maximum testing and anthropometry. Journal of Strength and Conditioning Research 2006 20 584-592.

51 Van Loon LJ, Koopman R, Stegen JH, Wagenmakers AJ, Keizer HA \& Saris WH. Intramyocellular lipids form an important substrate source during moderate intensity exercise in endurance-trained males in a fasted state. Journal of Physiology 2003553 611-625.

52 Mabuchi K \& Sreter FA. Actomyosin ATPase. II. Fiber typing by histochemical ATPase reaction. Muscle and Nerve 19803 233-239.

53 Schaart G, Hesselink RP, Keizer HA, Van Kranenburg G, Drost MR \& Hesselink MK. A modified PAS stain combined with immunofluorescence for quantitative analyses of glycogen in muscle sections. Histochemistry and Cell Biology 2004122 161-169.

54 Gosker HR, Van Mameren H, Van Dijk PJ, Engelen MP, Van Der Vusse GJ, Wouters EF \& Schols AM. Skeletal muscle fibre-type shifting and metabolic profile in patients with chronic obstructive pulmonary disease. European Respiratory Journal $200219617-625$.

55 Meyer K, Samek L, Schwaibold M, Westbrook S, Hajric R, Lehmann M, Essfeld D \& Roskamm H. Physical responses to different modes of interval exercise in patients with chronic heart failure-application to exercise training. European Heart Journal 199617 1040-1047.

56 Cauza E, Hanusch-Enserer U, Strasser B, Ludvik B, MetzSchimmerl S, Pacini G, Wagner O, Georg P, Prager R, Kostner K, Dunky A \& Haber $\mathrm{P}$. The relative benefits of endurance and strength training on the metabolic factors and muscle function of people with type 2 diabetes mellitus. Archives of Physical Medicine and Rehabilitation 200586 1527-1533.

57 Castaneda C, Layne JE, Munoz-Orians L, Gordon PL, Walsmith J, Foldvari M, Roubenoff R, Tucker KL \& Nelson ME. A randomized controlled trial of resistance exercise training to improve glycemic control in older adults with type 2 diabetes. Diabetes Care 200225 2335-2341.

58 Dunstan DW, Puddey IB, Beilin LJ, Burke V, Morton AR \& Stanton KG. Effects of a short-term circuit weight training program on glycaemic control in NIDDM. Diabetes Research and Clinical Practice $1998 \mathbf{4 0} 53-61$.

59 Holten MK, Zacho M, Gaster M, Juel C, Wojtaszewski JF \& Dela F. Strength training increases insulin-mediated glucose uptake, GLUT4 content, and insulin signaling in skeletal muscle in patients with type 2 diabetes. Diabetes 200453 294-305. 
60 Dunstan DW, Daly RM, Owen N, Jolley D, De Courten M, Shaw J \& Zimmet P. High-intensity resistance training improves glycemic control in older patients with type 2 diabetes. Diabetes Care 2002 25 1729-1736.

61 Cauza E, Hanusch-Enserer U, Strasser B, Kostner K, Dunky A \& Haber P. Strength and endurance training lead to different post exercise glucose profiles in diabetic participants using a continuous subcutaneous glucose monitoring system. European Journal of Clinical Investigation 200535 745-751.

62 Sigal RJ, Kenny GP, Boule NG, Wells GA, Prud'homme D, Fortier M, Reid RD, Tulloch H, Coyle D, Phillips P, Jennings A \& Jaffey J. Effects of aerobic training, resistance training, or both on glycemic control in type 2 diabetes: a randomized trial. Annals of Internal Medicine 2007147 357-369.

63 Dunstan DW, Mori TA, Puddey IB, Beilin LJ, Burke V, Morton AR \& Stanton KG. The independent and combined effects of aerobic exercise and dietary fish intake on serum lipids and glycemic control in NIDDM. A randomized controlled study. Diabetes Care 199720 913-921.

64 Wagner H, Degerblad M, Thorell A, Nygren J, Stahle A, Kuhl J, Brismar TB, Ohrvik J, Efendic S \& Bavenholm PN. Combined treatment with exercise training and acarbose improves metabolic control and cardiovascular risk factor profile in subjects with mild type 2 diabetes. Diabetes Care 200629 1471-1477.

65 Braith RW \& Stewart KJ. Resistance exercise training: its role in the prevention of cardiovascular disease. Circulation 2006113 2642-2650.

66 Toledo FG, Menshikova EV, Ritov VB, Azuma K, Radikova Z, Delany J \& Kelley DE. Effects of physical activity and weight loss on skeletal muscle mitochondria and relationship to glucose control in type 2 diabetes mellitus. Diabetes 200756 2142-2147.

67 Wilmore JH, Green JS, Stanforth PR, Gagnon J, Rankinen T, Leon AS, Rao DC, Skinner JS \& Bouchard C. Relationship of changes in maximal and submaximal aerobic fitness to changes in cardiovascular disease and non-insulin-dependent diabetes mellitus risk factors with endurance training: the HERITAGE Family Study. Metabolism 200150 1255-1263.

68 Evans EM, Racette SB, Peterson LR, Villareal DT, Greiwe JS \& Holloszy JO. Aerobic power and insulin action improve in response to endurance exercise training in healthy 77-87 yr olds. Journal of Applied Physiology 200598 40-45.

69 Schneider SH, Amorosa LF, Khachadurian AK \& Ruderman NB. Studies on the mechanism of improved glucose control during regular exercise in type 2 (non-insulin-dependent) diabetes. Diabetologia 198426 355-360.

70 Brooks N, Layne J, Gordon PL, Roubenoff R, Nelson ME \& Castaneda-Sceppa C. Strength training improves muscle quality and insulin sensitivity in Hispanic older adults with type 2 diabetes. International Journal of Medical Sciences 2007 4 1-27.

71 Hognestad A, Aukrust P, Wergeland R, Stokke O, Gullestad L, Semb AG, Holm T, Andreassen AK \& Kjekshus JK. Effects of conventional and aggressive statin treatment on markers of endothelial function and inflammation. Clinical Cardiology 2004 27 199-203.

72 Marketou ME, Zacharis EA, Nikitovic D, Ganotakis ES, Parthenakis FI, Maliaraki N \& Vardas PE. Early effects of simvastatin versus atorvastatin on oxidative stress and proinflammatory cytokines in hyperlipidemic subjects. Angiology 2006 57 211-218.

73 Pedersen BK. The anti-inflammatory effect of exercise: its role in diabetes and cardiovascular disease control. Essays in Biochemistry 200642 105-117.

74 Dela F, Von Linstow ME, Mikines KJ \& Galbo H. Physical training may enhance $\beta$-cell function in type 2 diabetes. American Journal of Physiology. Endocrinology and Metabolism 2004287 E1024-E1031.

75 UK Prospective Diabetes Study Group U. Intensive blood-glucose control with sulphonylureas or insulin compared with conventional treatment and risk of complications in patients with type 2 diabetes (UKPDS 33). Lancet $1998352837-853$.

76 Helge JW \& Dela F. Effect of training on muscle triacylglycerol and structural lipids: a relation to insulin sensitivity? Diabetes $2003 \mathbf{5 2}$ 1881-1887.

77 Gan SK, Kriketos AD, Ellis BA, Thompson CH, Kraegen EW \& Chisholm DJ. Changes in aerobic capacity and visceral fat but not myocyte lipid levels predict increased insulin action after exercise in overweight and obese men. Diabetes Care 200326 1706-1713.

78 Hurley BF, Nemeth PM, Martin WH, III, Hagberg JM, Dalsky GP \& Holloszy JO. Muscle triglyceride utilization during exercise: effect of training. Journal of Applied Physiology $1986 \mathbf{6 0} 562-567$.

79 Bergman BC, Butterfield GE, Wolfel EE, Casazza GA, Lopaschuk GD \& Brooks GA. Evaluation of exercise and training on muscle lipid metabolism. American Journal of Physiology 1999276 E106-E117.

80 Pruchnic R, Katsiaras A, He J, Winters C, Kelley DE \& Goodpaster BH. Exercise training increases intramyocellular lipid and oxidative capacity in older adults. American Journal of Physiology. Endocrinology and Metabolism 2004287 E857-E862.

81 Schrauwen-Hinderling VB, Schrauwen P, Hesselink MK, Van Engelshoven JM, Nicolay K, Saris WH, Kessels AG \& Kooi ME. The increase in intramyocellular lipid content is a very early response to training. Journal of Clinical Endocrinology and Metabolism 2003 88 1610-1616.

82 Dunstan DW, Vulikh E, Owen N, Jolley D, Shaw J \& Zimmet P. Community center-based resistance training for the maintenance of glycemic control in adults with type 2 diabetes. Diabetes Care $2006292586-2591$.

Received 7 October 2007

Accepted 10 October 2007 